\title{
Effect of attitudes and beliefs on exercise tolerance in chronic bronchitis
}

\author{
A D MORGAN, D F PECK, DIANA R BUCHANAN, G J R MCHARDY
}

\begin{abstract}
In 50 patients with chronic bronchitis the relation was assessed between exercise tolerance and pulmonary function and psychological factors, including subjective perception of exertion, mood, general psychiatric disturbance, and the attitudes and beliefs held by patients concerning themselves, their illness, and its treatment. Ventilatory capacity was significantly correlated with but a poor predictor of exercise tolerance. Subjective perception of exertion was most closely correlated with exercise tolerance. The distance walked in a 12-minute exercise test was significantly correlated with measurements of mood and with several attitudes and beliefs. Attitudes and beliefs greatly outweighed measurements of mood and ventilatory capacity as components in a multiple regression predicting distance walked in 12 minutes.

This method of psychological assessment emphasises the importance of attitudes and beliefs in respiratory disability and may have useful applications in rehabilitation in other chronic diseases.
\end{abstract}

\section{Introduction}

Chronic bronchitis with emphysema is a major cause of disability in the United Kingdom, and assessment of patients' disability is a common task for physicians. ${ }^{12}$ Measurement of pulmonary function is important in all cases, but in some patients other factors seem to contribute to their disability. Previous surveys

Department of Respiratory Medicine, University of Edinburgh, and Chest Unit, City Hospital, Edinburgh

A D MORGAN, MRCP, research fellow

DIANA R BUCHANAN, MRCP, registrar

G J R MCHARDY, FRCP, consultant clinical respiratory physiologist and part-time senior lecturer

Department of Psychiatry, University of Edinburgh, Royal Edinburgh Hospital, Edinburgh

D F PECK, BA, senior lecturer in clinical psychology of patients with chronic bronchitis have shown a greater than expected degree of psychiatric morbidity, ${ }^{34}$ and patients considered to have bronchitis and disproportionate breathlessness who were referred to Burns and Howell ${ }^{5}$ displayed features of both psychiatric disturbance and personality disorder. We previously used the 12-minute walking test as a useful test of everyday disability in patients with chronic bronchitis ${ }^{6}{ }^{7}$ but noted that its correlation with ventilatory capacity was not strong. Factors affecting effort and motivation must also be important, and we have therefore examined mood and general psychiatric disturbance, together with patients' beliefs and attitudes concerning their illness, to see whether such factors are related to physical performance.

\section{Patients and methods}

Patients were selected from those attending several respiratory clinics. All had chronic bronchitis fulfilling criteria laid down by the Medical Research Council ${ }^{8}$ together with airway obstruction and dyspnoea of Medical Research Council grades 3-5. They had not been referred on account of disproportionate breathlessness, gave no history of psychiatric illness, and were not taking antidepressant or anxiolytic drugs. We excluded patients who also had other medical conditions, such as cardiovascular or locomotor disorders, that would limit exercise tolerance. All patients who were approached agreed to participate.

Forced expired volume in one second and forced vital capacity were measured using a water-filled spirometer. The 12-minute walking distance ${ }^{6}$ was measured twice, with a rest of 20 minutes between tests, the better result being used in analysis. At the end of each walk the patients were asked to estimate their effort using Borg's scale of perceived exertion. ${ }^{9}$ Arterial blood was drawn from the brachial artery under local anaesthesia and analysed with Radiometer electrodes. Arterial samples were taken on the day of the tests from most patients, or within the preceding week from some who had recently been inpatients and were in a stable state.

Psychological assessments were of two kinds. In the first, mood disturbance was assessed with the multiple affect adjective checklist. ${ }^{10}$ Before walking the patients were asked to describe their feelings by selecting appropriate words from a list of 132 adjectives, from which numerical scores for anxiety, depression, and hostility were then derived. General psychiatric disturbance was assessed with the general health questionnaire, which provides a measure of non-specific psychiatric morbidity. ${ }^{11}$ Secondly, attitudes and beliefs were measured by means of the semantic differential. ${ }^{12}$ The patients were asked to consider certain beliefs and concepts about themselves, their illness, 
and its treatment; the concepts were set out as headings, below each of which was a set of pairs of adjectives of opposite meaning lying at each end of seven-point scales. The patients responded by marking an appropriate point on the scale between each pair, thus providing a numerical score. The concepts devised by Rutter ${ }^{13}$ were adapted for this study and are listed in table I, together with an example of the pairs used.

Values are given as means \pm 1 SD wherever appropriate. Correlation and multiple regression analysis were carried out using the SCSS system. ${ }^{14}$

TABLE I-Semantic differential, showing concepts used and example * of adjective scales (after Rutter ${ }^{13}$ )

What I think my treatment will be like: The treatment I receive will be successful* What I think my treatment will be like: The treatment
My bronchitis: My bronchitis is a long-term condition

My bronchitis: My bronchitis is a long

My family. The effect of my bronchitis on my family

Physical exercise: Physical exercise is good for me

Smoking: My general health

*Patients marked off an appropriate point between each pair of adjectives:

\begin{tabular}{|c|c|c|c|c|c|c|c|c|}
\hline $\begin{array}{l}\text { Unlikely } \\
\text { Possible } \\
\text { Improbable } \\
\text { True }\end{array}$ & 三 & E & E & E & z & $\bar{z}$ & I & $\begin{array}{l}\text { Likely } \\
\text { Impossible } \\
\text { Probable } \\
\text { False }\end{array}$ \\
\hline
\end{tabular}

\section{Results}

Fifty patients (38 men, 12 women) took part in the study; their ages ranged from 42 to 70 years (mean $60.5 \pm 6.8$ years). A wide range of ventilatory impairment was represented, with forced expired volume in one second ranging from 0.25 to 3.51 (mean $0.97 \pm 0.61$ ) and forced vital capacity from $1 \cdot 1$ to 5.21 (mean $2.59 \pm 0.961$ ), both measured at body temperature, pressure, and saturation. The range of arterial oxygen pressure was from 10.4 to $6.4 \mathrm{kPa}$ (78 to $48 \mathrm{~mm} \mathrm{Hg}$ ) (mean $8 \cdot 4 \pm 1 \cdot 1 \mathrm{kPa}(63 \pm 8 \mathrm{~mm} \mathrm{Hg}))$ and arterial carbon dioxide pressure from 4.4 to $7 \cdot 2 \mathrm{kPa}$ (33 to $54 \mathrm{~mm} \mathrm{Hg}$ ) (mean $5.5 \pm 0.8 \mathrm{kPa}(41 \pm 6$ $\mathrm{mm} \mathrm{Hg})$ ). The 12-minute walking distance ranged from 205 to 1460 m (mean $794 \pm 290 \mathrm{~m}$ ).

As in previous studies ${ }^{6} 7$ a significant correlation was found between ventilatory capacity and 12-minute walking distance, but the correlation coefficients for forced expired volume in one second $(r=0.26$, $p<0.05)$ and forced vital capacity $(r=0.29, p<0.02)$ were lower than previously reported. Of the variables studied, perceived exertion correlated most strongly $(\mathrm{r}=-0.49, \mathrm{p}<0.001)$ with 12-minute walking distance and was not itself significantly correlated with either forced expired volume in one second or forced vital capacity. Arterial oxygen and carbon dioxide pressures were not significantly correlated with the 12-minute walking distance.

\section{PSYCHOLOGICAL FACTORS}

A score greater than four out of 30 on the general health questionnaire has been taken to indicate the presence of general psychiatric disturbance, ${ }^{11}$ and 39 of the 50 patients had scores greater than this. Despite this evidence of psychiatric morbidity the individual scores did not correlate significantly with the distance walked. In contrast, scores for disturbances of mood assessed with the multiple affect adjective checklist in 49 patients showed significant negative correlations of increasing strength with anxiety $(r=-0.28, p<0.05)$, hostility $(r=-0.38, p<0.02)$, and depression $(r=-0.43, p<0.001)$. When beliefs and attitudes were analysed many beliefs held by the patients, particularly fear of exercise and negative attitudes towards treatment, correlated negatively with walking distance. Positive attitudes, with confidence in the value of treatment and taking exercise, correlated positively with exercise tolerance (table II).

We performed stepwise multiple regression analysis in 46 cases as some data from the semantic differential were missing in four. The analysis was carried out on all the factors that correlated significantly with walking distance, and permitted identification of those factors having independent effects and removal of those that were intercorrelated. Many factors including the scores obtained with the multiple affect adjective checklist, which describe mood, were thus eliminated. The remaining independent factors that contributed significantly $(p<0.05)$ to variance in the 12 -minute walking test were: perceived exertion (percentage variance $27 \%$ ); "treatment "will cure me" "14\%; "my bronchitis "is bad" " $14 \%$; "myself as I would like
TABLE II-Correlations between walking distance and attitudes and belie measured by semantic differential

\begin{tabular}{|c|c|c|c|}
\hline Concept & Patient's belief & $\mathbf{r}$ & $\mathrm{p} \widehat{\Omega}$ \\
\hline My treatment & $\begin{array}{l}\text { "Unsafe" } \\
\text { "Unsuccessful" } \\
\text { "Likely to be successful" } \\
\text { "Probably successful" } \\
\text { "Will cure me" }\end{array}$ & $\begin{array}{l}-0 \cdot 3 \\
-0 \cdot 31 \\
0 \cdot 31 \\
0 \cdot 32 \\
0 \cdot 39\end{array}$ & $\begin{array}{l}<0.025 \\
<0.02 \\
<0.0200 \\
<0.020 \\
<0.01\end{array}$ \\
\hline My bronchitis & $\begin{array}{l}\text { "Is very bad" } \\
\text { "Causes financial worries" }\end{array}$ & $\begin{array}{l}-0 \cdot 27 \\
-0 \cdot 3\end{array}$ & $\begin{array}{l}<0.032 \\
<0.02\end{array}$ \\
\hline $\begin{array}{l}\text { Myself as I would like } \\
\text { to be }\end{array}$ & "Delicate" & $0 \cdot 46$ & $<0.0 \overline{2}$ \\
\hline $\begin{array}{l}\text { Effect of my bronchitis } \\
\text { on my family }\end{array}$ & $\begin{array}{l}\text { "Bad" } \\
\text { "Small" }\end{array}$ & $\begin{array}{l}0 \cdot 25 \\
0 \cdot 27\end{array}$ & $\begin{array}{l}r .0 \\
<0.05 \\
<0.0 \text { क् }\end{array}$ \\
\hline Physical exercise & $\begin{array}{l}\text { "Dangerous" } \\
\text { "Good" }\end{array}$ & $\begin{array}{r}-0 \cdot 3 \\
0 \cdot 3\end{array}$ & $\begin{array}{l}<0.0 \% \\
<0.0 \text { 画 }\end{array}$ \\
\hline Smoking & "Awful" & $0 \cdot 29$ & $<0.0$ ? \\
\hline
\end{tabular}

to be-'delicate" " $13 \%$; "my treatment 'will be successful" " $40 \vec{\omega}$ forced vital capacity $4 \%$; and "smoking is awful" 3\%. (The percentage variance accounted for by each variable is the contribution of that. variable once any variable higher in the list has been accounted foris Thus subjective perception of exertion was the factor that accountes for the largest proportion of the variance in distance walked. The remaining psychological factors all represented attitudes and belie derived from the semantic differential and accounted for a substantial proportion of variance. Of the measurements of pulmonary function, only forced vital capacity remained in this analysis, and it accounted for only a small proportion of variance. The multiple regression equation read as follows: predicted 12-minute walking distance (m) $=561.5-36 \times$ perceived exertion $+52 \times$ "treatment will cure me" -84 $\times$ "bronchitis is bad" $+67 \times$ "wish to be delicate" $+49 \times$ "treatmerf will be successful" $+0.6 \times$ forced vital capacity $+28 \times$ "smoking awful"' (multiple $\mathrm{r}=0.89, \mathrm{p}<0.001$ ).

\section{Discussion}

Ventilatory capacity is a poor predictor of exercise tolerancs in chronic bronchitis, whether estimated by the patient ${ }^{15}$ के measured by a walking test. ${ }^{2}$ The wide prevalence of non-specificos psychiatric disturbance in patients with chronic bronchitis also well established. ${ }^{3}$ Our results indicate that impairment of everyday physical performance is more closely related to mook especially depression, than to the non-specific disturbanceg estimated by the general health questionnaire. When attitudes and beliefs are measured by techniques familiar in applies psychology they in turn appear to be of greater importance tha disturbances of mood or measurements of ventilatory capacity in predicting everyday exercise tolerance in chronic bronchitis In almost every instance (the exception being the wish for oneself to be delicate) these measurements quantify what man physicians believe intuitively. Measurement of attitudes and beliefs should therefore be of particular value in other types of chronic disability in which organic and psychological factor interact. Conditions such as angina pectoris, intermittente claudication, and chronic arthritis would seem particularli suitable for investigation. Measurement of beliefs should alsoy accompany objective measurements of performance in the investigation of any type of disability, and both deserve to be given a more prominent place in the traditional clinical history and examination than they have in the past.

In recent studies we noted that the 12-minute walking distance was improved after administration of bronchodilator drugs but that combined bronchodilator treatment producing further bronchodilation did not lead to a further increase if walking distance. ${ }^{16} 17$ The present study helps to explain thes findings by showing how small a part ventilatory capacity seems to play in predicting 12-minute walking distance. It alsర emphasises the importance of the patient's own estimate of the severity of exercise in determining his performance. The findings also suggest that in chronic bronchitis, when limitation of airflow may be only partially relieved by bronchodilators, 
greater emphasis should be given in rehabilitation to attempts to alter attitudes and beliefs. Structured supportive counselling, aimed at increasing confidence and reducing fear, may provide a means of considerably reducing disability.

We are grateful to Dr Brenda Rutter for generously providing material for the semantic differential. We thank the staff of the respiratory laboratory, City Hospital Edinburgh, for help with the pulmonary function tests and Mrs M M Jack for typing the manuscript.

\section{References}

1 Office of Health Economics. Preventing bronchitis. London: OHE, 1977.

2 Royal College of Physicians. Disabling chest disease: prevention and care. f $R$ Coll Physicians Lond 1981;15:69-87.

${ }^{3}$ Oswald NC, Walter RE, Drinkwater J. Relationship between breathlessness and anxiety in asthma and bronchitis: a comparative study. $\mathrm{Br}$ Med F 1970;ii:14-7.

4 Rutter BM. Some psychological concomitants of chronic bronchitis. Psychol Med 1978;7:459-65.

${ }^{5}$ Burns BH, Howell JBL. Disproportionately severe breathlessness in chronic bronchitis. $Q \mathcal{F}$ Med 1969;151:277-94.

${ }^{6}$ McGavin CR, Gupta SP, McHardy GJR. Twelve-minute walking test for assessing disability in chronic bronchitis. Br Med f 1976;i:822-3.
${ }^{7}$ McGavin CR, Artvinli M, Naoe H, McHardy GJR. Dyspnoea, disability, and distance walked: comparison of estimates of exercise performance in respiratory disease. $\mathrm{Br}$ Med $\mathcal{F} 1978$;ii:241-3.

${ }^{8}$ Medical Research Council. Classification of chronic bronchitis for clinical and epidemiological purposes. Lancet 1965 ; : $: 775-9$.

${ }^{9}$ Borg G. Perceived exertion as an indicator of somatic stress. Scand $\mathcal{f}$ Rehabil Med 1970;2:92-8.

10 Zuckerman M, Lubin B. Test manual for the multiple affect adjective check list. San Diego: Educational and Industrial Testing Service, 1965.

11 Goldberg DP. Psychiatric disorders. Lancet 1974;ii:775-9.

12 Osgood CE, Suci GJ, Tannenbaum PH. The measurement of meaning. Urbana, Illinois: University of Illinois Press, 1957.

${ }^{13}$ Rutter BM. Prognostic significance of psychological factors in management of chronic bronchitis. Psychol Med 1979;9:63-70.

14 Nie NH, Hull $\mathrm{CH}$, Franklin MN, et al. S.C.S.S.: a user's guide to the SCSS conversational system. New York: McGraw Hill, 1980.

15 Capel LH, Smart J. Obstructive airway disease. Measurement of effort tolerance and forced expiratory volume in bronchitis, emphysema and asthma. Lancet $1959 ; \mathrm{i}: 960-2$.

16 Leitch AG, Hopkin JM, Ellis DA, Merchant S, McHardy GJR. The effect of aerosol ipratropium bromide and salbutamol on exercise tolerance in chronic bronchitis. Thorax 1978;33:711-3.

17 Leitch AG, Morgan AD, Ellis DA, Bell G, Haslett C, McHardy GJR. Effect of oral salbutamol and aminophylline on exercise tolerance in chronic bronchitis. Thorax $1981 ; 36: 787-9$.

(Accepted 25 October 1982)

\title{
Low phospholipid arachidonic acid values in diabetic platelets
}

\author{
D B JONES， R D CARTER，B HAITAS， J I MANN
}

\begin{abstract}
Platelet aggregation is enhanced in diabetes mellitus, and platelets may be implicated in the pathogenesis of diabetic angiopathy. Increased platelet aggregation is probably mediated by the production of the proaggregatory prostaglandin thromboxane, which is synthesised from arachidonic acid (C20:4) by the action of the platelet enzymes cyclo-oxygenase and thromboxane synthetase.

The fatty acid composition of platelet phospholipid was measured in 20 normal controls, 10 insulin-treated diabetics with no or minimal retinopathy, and 10 insulintreated diabetics with proliferative retinopathy. The percentage of arachidonic acid was significantly higher in controls (mean $22.6 \%$ ) than in the diabetics with no or minimal retinopathy (mean $18.5 \% ; p<0.025$ ) and the diabetics with proliferative retinopathy (mean $14.6 \%$; $p<0.001)$. The percentage of linoleic acid was lower in controls (mean $8.9 \%$ ) than in the diabetics with no or minimal retinopathy (mean $12.6 \% ; p<0.01$ ) and diabetics with proliferative retinopathy (mean $13.1 \%$; $p<0.001)$. The mean percentage of linolenic acid was significantly lower in the diabetics with proliferative retinopathy $(2 \cdot 7 \%)$ than in the normal control group $(4.4 \% ; p<0.01)$. A significant negative correlation was found between the percentages of arachidonic acid and
\end{abstract}

Diabetes Research Laboratories and Department of Community Medicine and General Practice, University of Oxford, Radcliffe Infirmary, Oxford OX2 6HE

D B JONES, MRCP, research registrar

R D CARTER, MIST, senior laboratory scientific officer

B HAITAS, MRCP, research registrar

I I MANN, PHD, DM, lecturer in social and community medicine, and honorary consultant physician glycosylated haemoglobin $(\mathrm{Rs}=-0.58 ; \quad$ p $<0.001) . \quad$ A significant positive correlation was found between linoleic acid and the percentage of glycosylated haemoglobin ( $R s=0.51 ; p<0.01)$.

The reciprocal correlation between percentages of arachidonic acid and glycosylated haemoglobin suggests that diabetic control may influence thromboxane release and platelet activity directly and that low percentages of arachidonic acid reflect the increased degree of in-vivo activation.

\section{Introduction}

The control of platelet aggregation is influenced by two conflicting prostaglandins. Thromboxane $A_{2}$ is synthesised and released by platelets and promotes aggregation, ${ }^{1}$ while prostacyclin is produced by vascular endothelium and is antiaggregatory. ${ }^{2}$ Disturbed metabolism of either of these has been suggested as the cause of increased platelet aggregation in diabetes. ${ }^{34}$

Raised circulating concentrations of thromboxane $B_{2}$ (the metabolite of thromboxane $A_{2}$ ) have been shown in diabetics with retinopathy, though thromboxane production by platelets in vitro was low or normal. ${ }^{4}$

We have studied the phospholipid fatty acid composition of platelets from diabetics with minimal background or severe proliferative retinopathy because arachidonic acid represents the crucial substrate for production of thromboxane $A_{2}$. We also studied the relation between glycaemic control and altered composition of platelet fatty acids.

\section{Patients and methods}

We studied three groups of subjects: 20 normal controls, 10 insulin-treated diabetics with no or minimal retinopathy, and 10 